\title{
Universiteit
}

Leiden

The Netherlands

\section{Rough-and-tumble play and the regulation of aggression in preschoolers}

Veiga, G.; O'Connor, R.A.; Neto, C.; Rieffe, C.J.

\section{Citation}

Veiga, G., O'Connor, R. A., Neto, C., \& Rieffe, C. J. (2020). Rough-and-tumble play and the regulation of aggression in preschoolers. Early Child Development And Care, 1-13.

doi:10.1080/03004430.2020.1828396

Version: $\quad$ Publisher's Version

License: $\quad$ Licensed under Article 25fa Copyright Act/Law (Amendment Taverne)

Downloaded from: https://hdl.handle.net/1887/3263712

Note: To cite this publication please use the final published version (if applicable). 
Early Child

Development

and Care

\section{Early Child Development and Care}

\section{Rough-and-tumble play and the regulation of aggression in preschoolers}

\section{Guida Veiga, Rachel O'Connor, Carlos Neto \& Carolien Rieffe}

To cite this article: Guida Veiga, Rachel O'Connor, Carlos Neto \& Carolien Rieffe (2020): Roughand-tumble play and the regulation of aggression in preschoolers, Early Child Development and Care, DOI: $\underline{10.1080 / 03004430.2020 .1828396}$

To link to this article: https://doi.org/10.1080/03004430.2020.1828396

\section{Published online: 14 Oct 2020.}

Submit your article to this journal $₫$

Џll Article views: 659

Q View related articles $\asymp$

View Crossmark data $₫$ 


\title{
Rough-and-tumble play and the regulation of aggression in preschoolers
}

\author{
Guida Veiga (D) ${ }^{a, b^{\dagger}}$, Rachel $\mathrm{O}^{\prime}$ Connor (D) ${ }^{\mathrm{c}^{\dagger}}$, Carlos Neto ${ }^{\mathrm{b}}$ and Carolien Rieffe (D) ${ }^{\mathrm{c} d}$ \\ aDepartamento de Desporto e Saúde, Escola de Ciências e Tecnologia, Universidade de Évora, Évora, Portugal; \\ bLaboratory of Motor Behaviour, Faculdade de Motricidade, Universidade de Lisboa, Lisboa, Portugal; \\ 'Developmental Psychology, Leiden University, Leiden, The Netherlands; ${ }^{d}$ Department of Psychology and Human \\ Development, University College London, UK
}

\begin{abstract}
Learning to regulate aggressive impulses is a significant developmental milestone for preschoolers. To date, there is no consensus about whether rough-and-tumble play (RTP) is positively or negatively related to the regulation of aggression. This study examined the relation of RTP with children's levels of emotion regulation and aggression. RTP of 90 4-6 years old preschoolers was videotaped at the school playground and measured through parent questionnaires at home. Besides the amount (frequency and duration), the characteristics (i.e. dominance and emotional display) of father-child RTP were also examined. In both contexts, more RTP was not related to better emotion regulation in children. At school, RTP with peers was related to more physical aggression. At home, the frequency of RTP interactions was related to more emotion dysregulation and aggression. The display of negative emotions during father-child RTP interactions was related to poorer emotion regulation skills, and higher levels of aggression.
\end{abstract}

\section{ARTICLE HISTORY}

Received 10 July 2020

Accepted 18 September 2020

\section{KEYWORDS}

Playground; father-child; emotion regulation; aggressive behaviour; emotion socialization

The importance of play in young offspring for a healthy and adaptive development into adulthood is extensively documented and recognized by researchers from various disciplines and practitioners. Playing together with parents, siblings, and peers creates a joyful and stimulating environment to practice skills that are essential for life, in the short term and long term. For young humans, the skills that are needed for adulthood become increasingly complex and demanding, which is reflected in the different kinds of play that young children practice (Bjorklund, Periss, \& Causey, 2009). For example, in pretend play, children learn how to take on different social roles, negotiate, regulate their impulses, act out emotions to affect social interactions, and so on (Lillard et al., 2013). In exercise play, children run, jump, climb, improve their motor skills and coordination, and learn how to take turns and improve other social abilities (Pellegrini \& Smith, 1998; Veiga et al., 2016). There is, however, one kind of play that has not been uniquely related to positive outcomes rough-and-tumble play (RTP). RTP is a form of physical play that consists of active behaviours such as wrestling, chasing, and fleeing (Pellegrini, 1989). It would resemble aggression if not displayed in a playful atmosphere, characterized by positive affect, reciprocating roles, and sustained social interaction. RTP allows children to behave physically rough with one another, within the boundaries of the play setting. However, there is a controversy about whether RTP improves

CONTACT Guida Veiga greiga@uevora.pt E Departamento de Desporto e Saúde, Escola de Ciências e Tecnologia, University of Évora, Rua Romão Ramalho, 59, Évora 7000-671, Portugal

${ }^{\dagger}$ Comprehensive Health Research Centre (CHRC), Évora, Portugal

${ }^{\ddagger}$ School of Psychology, University College Dublin, Dublin, Ireland

(c) 2020 Informa UK Limited, trading as Taylor \& Francis Group 
children's emotion regulation skills (e.g. anger management), and decreases aggression (e.g. J. L. Hart \& Tannock, 2018; Peterson \& Flanders, 2005), or whether it has the opposite effect (e.g. Logue \& Harvey, 2009; StGeorge \& Freeman, 2017). The aim of this study is to examine the relationship between preschoolers' RTP, emotion regulation skills and aggressive behaviour.

As the most prevalent and ancient type of social play in mammals (Panksepp, 1998; Pellis \& Pellis, 2007), RTP has been argued to have clear evolutionary roots and functions, such as the safe practice of fighting skills and the establishment of social dominance (Boulton \& Smith, 1995; Pellegrini \& Smith, 1998). For example, studies with rodents showed that the engagement in RTP during the juvenile period improves emotion regulation, behavioural inhibition and social skills (Burgdorf, Kroes, \& Moskal, 2017; Panksepp, Burgdorf, Turner, \& Gordon, 2003; Van den Berg et al., 1999), whereas the deprivation of RTP has a negative long-term effect in social behaviour responsiveness (Hol, Van den Berg, Van Ree, \& Spruijt, 1999). Moreover, RTP has a positive effect on the establishment of rodents' social dominance, which results in decreased aggression (Pellis \& Pellis, 2007).

Although the animal studies have mainly focused on play between peers, when studying RTP in humans it is important to examine both father-child and peer-peer play interactions. Unlike other mammals, young humans have the longest period of dependency on their parents (Bjorklund et al., 2009). Throughout this extended time of immaturity, RTP is frequently engaged in with parents, and particularly with the father (MacDonald \& Parke, 1986; Paquette, Carbonneau, Dubeau, Bigras, \& Tremblay, 2003), and fathers equally engage in RTP with girls and boys (Fliek, Daemen, Roelofs, \& Muris, 2015). RTP among peers tends to increase during the preschool years (Pellegrini \& Smith, 1998), and recent studies show that its prevalence during preschool recess varies between $10 \%$ and $53 \%$ of social play time, depending on the type of playground (indoor versus outdoor, respectively; Lindsey \& Colwell, 2013; Veiga et al., 2016). However, the amount of RTP engaged in also depends on the gender of the child. Whether due to biological determinants, their direct environment or the wider social context, by the age of four many girls and boys tend to engage in different manners of play, with girls generally more often engaging in more domestic themes of play, with a focus on care and connection and boys more often engaging in more physically rough themes of play (Cherney, 2018; Scarlett, Naudeau, Salonius-Pasternak, \& Ponte, 2005). Indeed, as may be expected, when playing with their fathers, boys engage in more RTP than girls (Flanders, Leo, Paquette, Pihl, \& Séguin, 2009) and peer-peer RTP is also more frequent among boys than girls (Lindsey \& Colwell, 2013; Pellegrini \& Smith, 1998; Veiga et al., 2016). Less is known about the qualitative aspects of the RTP that boys and girls engage in. Previous research suggests that dominance is an important aspect of RTP (i.e. who physically dominates the other), which determines whether the RTP promotes adaptive or non-adaptive outcomes (Flanders et al., 2009, 2010; StGeorge \& Freeman, 2017).

Although aggression may appear to be part of RTP, it is not. Aggression is any behaviour intended to harm another person who does not want to be harmed (Baron \& Richardson, 2004). RTP implies no intent to harm, and compared to aggression involves different behaviours, different rules and positive affect (Romero, Pham, \& Goetz, 2014), such that partners often remain together after the play terminates (Fry, 1990; Storli, 2013). Besides the positive affect, an important key feature that distinguishes RTP from aggression is dominance swapping. Human dominance can be conceptualized as dyadic, affiliative relationship in which one individual is more likely to have ascendency over the other (Pellegrini et al., 2007). Hence, dominance swapping in RTP requires that the two people involved in RTP will often switch roles of who is dominant and who is submissive; even if one of the partners is clearly stronger, faster or smarter, that person will sometimes deliberately lose. Such dominance swapping allows for a balance between competition and cooperation levels, which enables the pleasure of the interaction and prevents the escalation into serious aggression and therefore the end of the play interaction (Pellis, Pellis, \& Reinhart, 2010). Although the escalation from RTP to real fighting can occur, it is relatively rare - only $3 \%$ of RTP interactions can be classified as aggression (Pellegrini, 1989; Pellegrini \& Perlmutter, 1988; Scott \& Panksepp, 2003), indicating that children are able to follow the rules to keep it playful. In fact, elementary school age children are 
already able to recognize RTP as friendly and not hurtful interactions (Smith, Smees, \& Pellegrini, 2004) and to distinguish RTP from real fighting bouts (Nabuzoka \& Smith, 1999).

Learning how to regulate angry feelings and aggressive impulses is a difficult skill for young children (Bradley, 2000; Tremblay, 2000). RTP is an arousing, physically challenging interaction, where children can pretend to be aggressive against the other and to be attacked by the other. Therefore, for RTP to be fun, children need to accurately read the other's affective and intentional indicators, control their anger impulses, moderate their strength levels, plan and monitor social goals, and cope with the frustration of losing (Flanders et al., 2013; Peterson \& Flanders, 2005). In other words, RTP gives children the opportunity to practice anger regulation within a safe environment, which is especially the case when the RTP is with a loving parent (Paquette, 2004; Peterson \& Flanders, 2005).

Despite the assumption that RTP increases emotion regulation, the systematic review of StGeorge and Freeman (2017) showed that very few studies support the positive contribution of RTP to preschoolers' capacity for emotion regulation. Concerning peer-peer RTP, only one study found that RTP is associated with better emotion regulation skills, both concurrently and longitudinally, and only for boys (Lindsey \& Colwell, 2013). Different findings appear when RTP occurs within a parentchild dyad. These studies generally found that father-child RTP is related to more emotional dysregulation (e.g. inability to calm down) rather than emotional regulation (Flanders et al., 2009, 2010; Paquette et al., 2003). A longitudinal study with infants found that RTP has no effect on the development of self-regulation (Nakagawa \& Sukigara, 2014). Only one study found that father-child RTP is associated with emotion regulation (Barth \& Parke, 1993), but the play situations in that study were initiated by the researchers, and the RTP also contained other forms of physical contact, such as tickling.

Two factors seem to be important for father-child RTP. First, the father should set limits on the play by controlling the child's aggressive impulses (Flanders et al., 2009, 2010). Research shows that when fathers fail to set limits, the child can become more hostile rather than less hostile (Barth \& Parke, 1993). In addition, for children whose fathers were less dominant during the play interaction, higher frequencies of father-child RTP at preschool age predicted more aggression and poor emotion regulation abilities 5 years later (Flanders et al., 2010).

According to social learning theory (Bandura, 1973), children will copy and eventually internalize the role models available to them. If the models, do not restrain aggressive impulses, children will be deprived from learning how to maintain RTP interactions within the playful boundaries by self-regulating angry feelings and aggressive impulses. This is especially true when the model being observed is a parent that the child might idolize.

Second, the affective climate should be positive, i.e. the display of positive emotions should be guaranteed. One study found that children, who engaged in play with their fathers in a negative climate in which negative emotions were reciprocated, were rated by their teachers to be more aggressive in school compared to other children (Carson \& Parke, 1996). In this study, fathers and children were instructed to play a specific physical game, which consisted of catching each other's hands before the other could pull them away, in an alternating pattern, however this game did not involve wrestling, chasing, or fleeing. To date, no study has yet addressed the extent to which emotion display moderates the relationship between father-child RTP and the regulation of aggression. Although it usually occurs in a playful atmosphere, RTP involves high levels of physiological arousal, which is known to decrease the ability to reappraise the emotionally charged situation (Roberton, Daffern, \& Bucks, 2012; Rydell et al., 2008). If children mislabel physiological arousal from RTP as anger, it could increase their aggression levels (e.g. Zillman, 1979).

In terms of both of these qualitative aspects of RTP, the role of gender must also be considered. As RTP seems to be more popular among boys (Colwell \& Lindsey, 2005; Lindsey \& Colwell, 2013; Veiga et al., 2016), we may expect more dominating behaviour in boys than we would in girls in these circumstances. We also know that in a variety of situations, boys tend to express more negative emotions, whereas girls express more positive emotions (Chaplin \& Aldao, 2013). Although there are undoubtedly gender differences in these domains, they do not appear to moderate the relation between children's physical aggression or emotion regulation (Flanders et al., 2009, 2010). 


\section{Overview of the current study}

The aim of this study was to examine the relation between RTP and children's levels of emotion regulation and aggression. To date, no study has addressed RTP at both school and home. At school we examined peer-peer RTP, and at home we examined father-child RTP, given the prevalence and the significance of RTP in father-child interactions (Ross \& Taylor, 1989). Because scholars have emphasized the need for research to examine the influence of the qualitative aspects of the father-child RTP interactions, we investigated both the amount (frequency and duration), as well as the characteristics (i.e. dominance and emotional display) of father-child RTP on emotion regulation and aggression in preschool children (Flanders et al., 2010). In line with previous studies, we predicted that father-child RTP characterized by children's dominance and a display of negative emotions would be related to poorer emotion regulation skills, and higher levels of aggression. Given the inconsistency between previous empirical findings and theories, no specific hypotheses were formed concerning the relationship between peer-peer RTP with levels of emotion regulation and aggression.

\section{Method}

\section{Participants}

A sample of 98 families whose children were attending a preschool Institution in the Educative Region of Lisbon, Portugal, were invited to participate in this study. Of these, 97 families volunteered to participate in the research (consent rate $=99 \%$ ), and $90(92 \%)$ completed all components of the project. The other 7 families who did not complete all components were three single-parent families who were not interested in participating and other four families who forgot to answer to one of the questionnaires. The final sample consisted of 53 boys and 37 girls, 46-71 months old (see Table 1 for demographics).

Parent education and job status were ascertained through a questionnaire. Education was coded as follows: $n o$ / primary education $=1$, lower general secondary education $=2$, higher general secondary education $=3$, college/ university education $=4$. Parent jobs were assigned a ranking of either low, medium, or high, depending on the typical income range for that occupation, as defined by the Portuguese Classification of Jobs.

\section{Materials and procedure}

The study was approved by the Scientific Committee of the Faculty of Human Kinetics - University of Lisbon, Portugal, and carried out in accordance with the standards set by the Declaration of Helsinki. Written parental consent was obtained for all children prior to data collection. The collected data were fully encrypted to ensure the privacy of the participants.

Table 1. Demographic characteristics of participants.

\begin{tabular}{|c|c|c|c|}
\hline & Total $(n=90)$ & Boys $(n=53)$ & Girls $(n=37)$ \\
\hline Age, mean $(S D)$, months & $56.89(5.40)$ & $56.92(4.69)$ & $57.03(6.21)$ \\
\hline Age, range, months & $46-71$ & $46-67$ & $46-71$ \\
\hline \multicolumn{4}{|l|}{ Socioeconomic status } \\
\hline Maternal education, mean $(S D)^{a}$ & $3.09(.79)$ & $2.98(.77)$ & $3.22(.80)$ \\
\hline Paternal education, mean $(S D)^{a}$ & $2.88(.69)$ & $2.80(.63)$ & $3.00(.77)$ \\
\hline Maternal job, mean $(S D)^{\mathrm{b}}$ & $2.02(.78)$ & $2.04(.71)$ & $2.00(.87)$ \\
\hline Paternal job, mean $(S D)^{\mathrm{b}}$ & $2.24(.71)$ & $2.33(.67)$ & $2.10(.77)$ \\
\hline
\end{tabular}

Note: ${ }^{\mathrm{a}} 1=$ no/primary education, $2=$ lower general secondary education, $3=$ higher general secondary education, $4=$ college/ university.

${ }^{\mathrm{b}} 1=$ low, 2 = average, 3 = high. 


\section{Observations}

Peer-peer RTP at school was obtained by videotaping outdoor recess, and coding children's engagement in RTP. Three research assistants videotaped children one-by-one according to a predetermined random list of names, for 3-minute periods. A total of 562 videos were collected for 5 continuous weeks, for an average of 6 videos per child (range $=5-9$ videos, dependent on the availability of the child; i.e. in case of illness or other circumstances unrelated to the data collection). Each 3-minute video was coded in 15-second intervals. RTP was defined as active playful behaviour, which appears to be aggressive, but is performed with an obvious 'play face' (i.e. smiling or otherwise clearly indicating absence of anger or aggression), such as capture or rescue, submit or vanquish, or attack or flee. Peer-peer RTP was coded as either present $(=1)$ if it occurred within the 15 second interval or absent $(=0)$ if it did not occur at all within the interval by two research assistants. Children then received a score representing the proportion of segments that they engaged in RTP (i.e. the number of segments that the child showed RTP, divided by the child's total number of 15-second segments). Each research assistant coded half of the videos independently, and $30 \%$ of the videos were double coded in order to ensure suitable levels of reliability across coders $(K=.82)$.

\section{Questionnaires}

Questionnaires were translated from either French or English into Portuguese, which was done by native Portuguese speakers using procedures recommended in previous research (Brislin, 1986). Three native Portuguese speakers, who were also fluent in French and English, back-translated the Portuguese versions into the original languages. Native French and English speakers then compared the translated questionnaires to the original questionnaires.

RTP at home (frequency) was obtained by asking mothers to indicate how often their child engaged in play fights (i.e. RTP) at home using one 5-point item ('Without counting school time, how often does your child engage in play fights?'; $1=1-3$ times a year, 2=1-3 times a month, $3=$ 1-2 times a week, 4=3-4 times a week, $5=5$ or more times a week), combined with fathers' responses to two 5-point items from the 'Père-En-Jeux' (Father in Play) questionnaire (Flanders et al., 2009; Paquette et al., 2003; 'How often does your child play fight with his/ her brothers/sisters?'; $1=$ (almost) never, $2=1-3$ times a month, 3=1-2 times a week, $4=3-4$ times a week, $5=5$ or more times $a$ week and 'Does your child engage in play fighting with your wife?' ; $1=($ almost) never, $2=$ rarely, 3 = sometimes, $4=$ many times, and $5=$ (almost) always; Cronbach $a=.44)$, to create a composite score representing frequency of RTP at home.

RTP at home (duration) was obtained from fathers' responses on one 5-point item from the 'PèreEn-Jeux' questionnaire: 'On average, how long is the play fight?' to which fathers were required to respond with an estimate number of minutes.

The characteristics of father-child RTP were examined through the 'Père-En-Jeux' questionnaire, completed by fathers. Previous research has revealed good reliability between this questionnaire and observational data of father-child interactions at play (Dubé, 2012). We focused on two features of play: dominance and emotional display.

Dominance was obtained by asking fathers the extent to which their child tended to dominate the play fight using a 4-item scale, where higher scores indicate a greater tendency of the child to dominate (e.g. 'Does your child try to dominate the play-fight?', 'Overall, how often do you think your child feels he/ she has won the play fight?'; Cronbach $a=.71$ ):

Negative Emotional Display was obtained by asking fathers to report how frequently the play fight was embedded or ended in negative emotions using a 2-item, 5-point scale, where higher scores indicate a higher frequency of negative emotions (e.g. 'Does your child get angry during or after the play fight?' and 'It can happen that the play fight ends with the child in tears, sored or upset. How often does it happen?'). For both Dominance and Negative Emotional Display, scores were standardized by converting them to Z-scores. 
Emotion Dysregulation was measured using the 8-item Emotion Dysregulation parent-report subscale of the Emotion Expression Questionnaire, completed by mothers, where higher scores indicate higher dysregulation (Rieffe, Ketelaar, \& Wiefferink, 2010 (e.g. 'Is your child easy to calm down when angry?' and 'Is your child easy to calm down when sad?'; 1 = very easy to $5=$ very hard; Cronbach $a$ $=.73$ ).

Aggression was assessed through the Aggressive Behaviours Questionnaire (Dodge \& Coie, 1987), completed by mothers, where higher scores indicate higher levels of aggression. It included three items assessing reactive aggression (e.g. When teased, strikes back) and three items assessing proactive aggression (e.g. 'Uses physical force to dominate others'; $1=$ almost never to $5=$ almost always; Cronbach $a=.71$ ) which were combined to form an aggression composite score.

\section{Statistical analyses}

First, descriptive data (mean and standard deviation) were gathered for boys and girls separately, and $t$-tests were conducted to test for gender differences. Second, Pearson's correlations were calculated between the RTP variables. Third, Pearson product-moment correlations were calculated between age, the amount of RTP at school and at home, the characteristics of father-child RTP and emotion dysregulation, and aggression for all children, and for boys and girls separately. Fisher transformations were used to examine the differences between the correlations for boys and girls. Finally, two hierarchical regression analyses were carried out with emotion dysregulation and aggression as dependent variables. To reduce multicollinearity, all RTP variables were centred by subtracting the mean. Gender and RTP at home were entered at Step 1, and child's dominance and negative emotional display were added at Step 2. In Step 3, the interaction terms with gender were added to examine whether the effects of the independent variables vary as a function of gender. The pooled regression coefficients were examined to see what variables contributed uniquely to the prediction of emotion dysregulation and of aggression. The data that support the findings of this study are available from the corresponding author upon request.

\section{Results}

\section{Gender differences}

Descriptive data of all variables for boys and girls are displayed in Table 2. Boys engaged in RTP at school more frequently than girls, $t(88)=3.57, p=.001, d=0.76$. It was also reported that boys engaged in RTP at home more frequently than girls, $t(88)=4.78, p<.000, d=.76$, but the duration of the RTP did not differ significantly between groups. Boys' fathers reported higher frequencies of child's dominance, $t(88)=3.85, p<.001, d=0.75$ and of negative emotional display in RTP interactions, $t(88)=2.19, p=.031, d=0.47$ than girls' fathers did.

\section{Relations between variables}

Frequency of RTP at school was positively associated with child's dominance during father-child RTP. Both frequency and duration of RTP at home were positively associated with all variables, with the exception of RTP at school. Dominance and negative emotional display were positively associated. See Table 3 for all correlations between RTP variables.

Table 4 shows the correlations between age, RTP at school, RTP at home and RTP characteristics (i.e. dominance and emotional display) and our two outcome variables: emotion dysregulation and aggression. When significant gender differences are present, correlation coefficients are presented for each gender (boys/ girls). As can be seen in Table 4, there were significant gender differences for the correlation between RTP at school and emotion dysregulation $(z=-2.36, p=.018)$ and for the correlation between negative emotional display and aggression $(z=-2.58, p=.010)$. Because 
Table 2. Internal consistencies, means and SDs for measures of rough-and-tumble play, emotion dysregulation and physical aggression.

\begin{tabular}{lcc}
\hline & \multicolumn{2}{c}{ Mean (SD) } \\
\cline { 2 - 3 } & $\begin{array}{c}\text { Boys } \\
(n=53)\end{array}$ & $\begin{array}{c}\text { Girls } \\
(n=37)\end{array}$ \\
\hline Instruments (min-max) & & \\
\hline Play observation & $.23(.15)$ & $.12(.13)$ \\
$\quad$ RTP at school $(0-1)^{* *}$ & & $1.66(.88)$ \\
Parent questionnaires (1-5) & $2.55(.83)$ & $6.69(9.37)$ \\
$\quad$ RTP at home (frequency)** & $8.50(10.17)$ & $2.33(.50)$ \\
$\quad$ RTP at home (duration) & $2.33(.43)$ & $1.75(.62)$ \\
Emotion dysregulation & $1.91(.44)$ & $4.33(.83)$ \\
Physical aggression & & $-.49(.83)$ \\
$\quad$ RTP Father Questionnaire & $4.17(.88)$ & $-.26(.78)$ \\
Father-child play (1-5) & $.13(.81)$ & \\
Child's dominance** & & \\
$\quad(z$-scores) & $.17(1.01)$ & \\
Negative emotional display* & & \\
$\quad(z$-scores) & &
\end{tabular}

Table 3. Correlations between rough-and-tumble play variables $(n=90)$.

\begin{tabular}{lllll}
\hline & 2 & 3 & 4 & 5 \\
\hline 1. RTP at school & .17 & .06 & $.34^{* * *}$ & .19 \\
2. RTP at home (frequency) & & $.48^{* * *}$ & $.50^{* * *}$ & $.36^{* * *}$ \\
3. RTP at home (duration) & & $.44^{* * *}$ & $.39^{* * *}$ \\
4. Child's dominance & & $.52^{* * *}$ \\
5. Negative emotional display & & \\
\hline Note. ${ }^{*} p \leq .05 ;{ }^{* *} p \leq .01 ;{ }^{* * *} p \leq .001$ (two-tailed). & &
\end{tabular}

significant gender differences were obtained, gender was included as an interaction term in the regression analyses. With the exception of RTP at school, all RTP variables were related to emotion dysregulation rather than emotion regulation. There were also significant positive correlations between the frequency of RTP (both at school and at home) and aggression.

\section{Predictors of emotion dysregulation and physical aggression}

Hierarchical multiple regression was used to assess the predictive ability of RTP variables on emotion dysregulation and physical aggression (see Table 5). Due to the observed gender differences in RTP variable relations with the two dependent variables (see Table 4), Gender was included in Step 1 of the regression model, along with frequency and duration of RTP at home. Step one accounted for $20 \%$ of the variability in emotion dysregulation and $15 \%$ of the variability in physical aggression. The frequency of RTP at home was a significant predictor of both emotion dysregulation $(\beta=.257$, $p=.049)$ and aggression $(\beta=.478, p=.001)$, whereas the duration of RTP at home predicted only

Table 4. Correlations of age, rough-and-tumble play, father-child play with mother-reported emotion dysregulation and physical aggression $(n=90)$.

\begin{tabular}{lcc}
\hline & Emotion dysregulation & Physical aggression \\
\hline Age & -.05 & -.06 \\
RTP at school & $-.27^{\mathrm{a}} / .25^{\mathrm{b}}$ & $.25^{*}$ \\
RTP at home (frequency) & $.35^{* * *}$ & $.41^{* * *}$ \\
RTP at home (duration) & $.42^{* * *}$ & $-.46^{\mathrm{a}} /-.32^{\mathrm{b} * *}$ \\
Child's dominance & $.24^{*}$ & $.38^{* * *}$ \\
Negative emotional display & $.36^{* * *}$ & $.23^{\mathrm{a}} / .67^{\mathrm{b} * * *}$ \\
\hline
\end{tabular}

Note. ${ }^{*} p \leq .05 ;{ }^{* *} p \leq .01 ;{ }^{* * *} p \leq .001$ (two-tailed); ${ }^{a}$ boy, ${ }^{\text {b }}$ girl. 
Table 5. Hierarchical regression analyses for child's rough-and-tumble play, dominance and negative emotional display on emotion dysregulation and physical aggression $(n=90)$.

\begin{tabular}{|c|c|c|c|c|c|c|}
\hline & \multicolumn{3}{|c|}{$\begin{array}{l}\text { Emotion dysregulation } \\
\qquad n=90\end{array}$} & \multicolumn{3}{|c|}{$\begin{array}{l}\text { Physical aggression } \\
\qquad n=90\end{array}$} \\
\hline & $R^{2}$ adj & $\beta$ & $p$ & $R^{2} a d j$ & $\beta$ & $p$ \\
\hline Step 1 & .20 & & $<.001$ & .15 & & $<.001$ \\
\hline Gender & & .189 & .101 & & .159 & .177 \\
\hline RTP at home (frequency) & & .257 & .049 & & .478 & .001 \\
\hline RTP at home (duration) & & .314 & .010 & & -.026 & .834 \\
\hline Step 2 & .24 & & $<.001$ & .20 & & $<.001$ \\
\hline Gender & & .219 & .056 & & .187 & .111 \\
\hline RTP at home (frequency) & & .180 & .188 & & .404 & .005 \\
\hline RTP at home (duration) & & .223 & .070 & & -.116 & .356 \\
\hline Child's dominance & & .061 & .645 & & .041 & .761 \\
\hline Negative emotional display & & .263 & .025 & & .279 & .021 \\
\hline Step 3 & .29 & & $<.001$ & .24 & & .001 \\
\hline Gender & & .204 & .073 & & .166 & .156 \\
\hline RTP at home (frequency) & & .129 & .371 & & .331 & .028 \\
\hline RTP at home (duration) & & .322 & .017 & & -.103 & .452 \\
\hline Child's dominance & & .123 & .346 & & .015 & .910 \\
\hline Negative emotional display & & .247 & .047 & & .387 & .003 \\
\hline Gender $\times$ RTP at home (fre) & & -.260 & .073 & & .012 & .933 \\
\hline Gender $\times$ RTP at home (dur) & & .242 & .083 & & .091 & .525 \\
\hline Gender $\times$ Child's dominance & & -.158 & .214 & & -.083 & .524 \\
\hline Gender $\times$ Negative emotional display & & -.017 & .890 & & .285 & .027 \\
\hline
\end{tabular}

emotion dysregulation $(\beta=.314, p=.010)$. Gender was not a significant predictor of either dependent variable.

After entry of child's dominance and negative emotional display in Step 2, the model explained $24 \%$ of the variance in emotion dysregulation and $20 \%$ of the variance in aggression. Frequency of RTP at home was a positive predictor of aggression $(\beta=.404, p=.005)$. Negative emotional display was a positive predictor of both emotion dysregulation $(\beta=.263, p=.025)$ and physical aggression $(\beta=.279, p=.021)$.

Adding the interactions with Gender in Step 3 resulted in an increase in model fit; $29 \%$ for emotion dysregulation and $24 \%$ for physical aggression. In terms of emotion dysregulation, duration of RTP at home remained a significant predictor $(\beta=.322, p=.017)$, as well as negative emotional display $(\beta=.247, p=.047)$. Frequency of RTP at home $(\beta=.331, p=.028)$ and negative emotional display $(\beta=.387, p=.003)$ remained significant predictors of physical aggression. In addition, gender interacted with negative emotional display to positively predict aggression $(\beta=.285, p$ $=.027$ ), which confirms the correlations in Table 4 , demonstrating an association between negative emotional display and aggression in girls but not in boys.

\section{Discussion}

RTP is perhaps the most controversial form of play. Whereas some parents, educators, and academics discourage RTP (e.g. Boyd, 1997; Holland, 2003), others argue that RTP is an opportunity to learn how to regulate angry feelings and aggressive behaviour (e.g. Paquette, 2004; Pellis \& Pellis, 2012; Tremblay, 2006). Given the prevalence of RTP within peer and father-child interactions, the central purpose of this study was to examine the extent to which RTP is related to emotion regulation skills and aggressive behaviours. The main finding was that in both contexts (i.e. at school and at home) more RTP was not related to better emotion regulation in children. For both genders, the frequency and length of RTP interactions at home were related to more emotion dysregulation, whereas both RTP at school and at home were related to more aggression.

Yet, when the level of dominance that children had over the RTP at home, and the level of negative emotional display during the father-child interaction were accounted for, as well as the 
moderating effect of gender, frequency of RTP at home was no longer associated with emotion dysregulation. However, the typical length of a bout of RTP at home was still an important factor, whereby children who engaged in RTP for longer periods at a time had worse emotion regulation skills. We also found that the display of negative emotions itself was related to more emotion dysregulation. This indicates that RTP at home might be harmless to children's emotion dysregulation when fathers keep the rules clear, exert control, are warm and sensitive to the child, thus preventing RTP from escalating, which may create a negative affective climate. The fact that exposure to negative emotions in the home impairs children's development of emotion regulation skills is not new (Eisenberg, 2000). Furthermore, perhaps limiting the duration of RTP interactions at home could also be considered another boundary condition (i.e. time limit) that facilitates fun and harmless RTP.

A different scenario emerged regarding children's aggression. The frequency of RTP at home was associated with more aggression, even when dominance and negative emotional display were accounted for. However, the incidence of RTP at home was not the only variable to lend a significant contribution to aggression. The display of negative emotions was also related to children's aggression. In line with the social learning theory, these outcomes suggest that the more children engage in RTP at home with fathers who fail to maintain a positive affective climate, the more they are repeatedly exposed to an aggressive role model, where they learn and practice how to behave aggressively themselves. Besides, these outcomes are in line with the idea that warmth and sensitivity to the child are an indicator of high-quality RTP interactions (Fletcher, StGeorge, \& Freeman, 2013)

It is important to note that the relationship between the display of negative emotions during RTP at home and children's aggression was moderated by gender; negative emotional display was only related to girls' physical aggression. It is possible that RTP interactions are more stressful for girls than boys. In fact, previous research has shown that in preschool years, boys display more physical aggression than girls, whereas girls display more relational aggression (e.g. excluding child from the peer group, ignoring a peer, etc.) than boys (e.g. Crick, Casas, \& Mosher, 1997; Crick et al., 2006). Such differences are even more evident during free play interactions (Ostrov \& Keating, 2004). Moreover, girls show more distress after engaging in or observing an episode of physical aggression than boys (Ferguson \& Eyre, 2000). Future research should focus on the possible causal effect of physical and relational aggression on the emotional and social development in girls, as to date the direction of the relationship between these factors has not been examined.

The outcomes of the present study support the hypothesis raised by previous research (Flanders et al., 2010, 2013) by showing that the affective climate of father-child RTP interactions at home is indeed an important aspect to account for. This is likely due to the fact that fathers are important models for emotion regulation skills and that negative emotions might lead to over-arousal and lack of control, therefore impeding children from practicing emotion regulation skills. More studies focusing on the particular role of fathers in emotion socialization are needed to test this premise.

In addition, engaging in RTP at school does not seem to be a positive behavioural indicator, given that children who most engaged in RTP at school were also rated by their parents as more aggressive. Higher levels of aggression might be the underlying reason for preschoolers who frequently engage in RTP being rated as less socially competent than their peers (Colwell \& Lindsey, 2005; C. H. Hart, DeWolf, Wozniak, \& Burts, 1992; Ladd \& Price, 1987). Although we are aware of the positive relationship between RTP and social competence (Pellegrini, 1988, 1989) and of the positive effect of RTP on aggressive behaviour previously found, these studies were conducted with older children (Carraro \& Gobbi, 2018) and adolescents (Carraro, Gobbi, \& Moè, 2014). Possibly, decoding RTP from real aggression and regulating arousal during RTP might be especially challenging for preschoolers, giving their less mature brain development (Perlman \& Pelphrey, 2011). Considering these findings together with the fact that RTP peaks at an older age (Pellegrini \& Smith, 1998), and with the extensive theoretical framework arguing that this form of play has the immediate 
function of practicing social signalling skills (Bjorklund \& Pellegrini, 2000), it seems plausible that the functions of RTP might change across children's development.

Note, however, that this study has some notable limitations. First, this study was cross-sectional, and therefore we are unable to draw conclusions about the causality of reported relations among variables. For example, the direction of causality might be reversed. That is, children who are aggressive to begin with might be more likely to engage in RTP at home. Likewise, a third variable might account for both RTP at home and aggression, such as having an aggressive father. Aggressive fathers might be more likely to engage in RTP with their children, and also might be more likely to have aggressive children (due to some combination of genes and environment). Also, we must consider the potential role of emotion contagion, whereby emotions associated with aggression, such as anger, may be expressed by parents and mirrored by children (Halberstadt, Beale, Meade, Craig, \& Parker, 2015). The present design cannot evaluate these alternative explanations. Second, the cross-contextual design of this study involving different methods of data collection (i.e. systematic observation and questionnaires) demands a cautious interpretation of the findings. The measures of both the amount and the characteristics of RTP at home were based on parents' reports. Moreover, our measure of the duration of RTP at home was measured by a single item and based on the mothers' subjective estimate. Future studies could examine RTP with fathers using both observational measures of RTP quality (e.g. Fletcher et al., 2013) and self-report measures, to ensure greater objectivity of measures. Finally, the present study considered gender as a dichotomous characteristic. This should be considered when interpreting the results and future research may work to understand RTP across a wider range of genders.

This research provides preliminary evidence of the efficacy of the relationship between RTP and preschoolers' aggression and emotion dysregulation. However, there are several interesting avenues for future research that would extend these findings and address the limitations mentioned above. First, future designs could also target other types of RTP (e.g. chasing and fleeing) and combine selfreport measures with observational data to improve the validity of the outcomes. Second, future research could address the father-child relationship in order to better understand the pathway between RTP interactions and development of aggressive behaviours. Finally, it would be worthwhile to implement and monitor a programme teaching fathers how to sustain positive and playful RTP interactions with their children, in order to investigate the effects on children's aggression and emotion regulation.

\section{Conclusion}

Our findings show that engaging in RTP is related to increased aggression and emotional dysregulation in preschoolers. However, this relationship is influenced by the context and the emotional display of father-child relationship. Our findings suggest that RTP can be harmless, when the parent takes control and when the climate is ruled by positive emotions.

\section{Disclosure statement}

No potential conflict of interest was reported by the author(s).

\section{Notes on contributors}

Guida Veiga obtained her Ph.D. in Human Kinetics from Lisbon University in 2015. She was an invited assistant professor at the Sports and Health Department of Évora University from 2009 to 2015, and she now has a tenured position as an assistant professor. Guida has been focused on the role of play and other body-oriented approaches (such as touch and relaxation) on socio-emotional and motor development. She has also been focused on assessment methods, such as systematic observation, sensor technology, or biological health indicators. In 2016, Guida won an Award for Smartest City Project of the Netherlands. Since 2017 Guida has been the director of the bachelor on Psychomotor Therapy at the University of Évora. 
Rachel O'Connor is a Ph.D. candidate at the Developmental and Educational Psychology unit of the Institute of Psychology at Leiden University. Rachel obtained her Master's degree in Child \& Adolescent Psychology at Leiden University in 2018. She also holds a Bachelor of Arts in Psychology from University College Dublin. Rachel has worked in a variety of clinical settings with both children and adults with autism, ADHD, and a range of mental health conditions. Rachel is currently also completing professional training as a clinical psychologist at University College Dublin, whereby she is working for the Irish Health Service Executive in mental health services.

Carlos Neto, Ph.D., is a full professor at Lisbon University - Portugal. He has been studying children's play and development for more than 40 years and is the Portuguese delegate of the International Play Association. He was also the founder of the National Society of Physical Education.

Carolien Rieffe obtained her PhD from Vrije University in Amsterdam, the Netherlands. She had a tenured position at the Institute of Education, University of London, UK, as an assistant professor (2001-2004), until she started at Leiden University in 2004. In 2010 the NSDSK (Dutch Foundation for the Deaf and Hard of Hearing Child, Amsterdam) installed an endowed chair for Carolien at Leiden University, who then became professor by special appointment in social and emotional development for 10 years. Since 2015, she is also Honorary Professor at UCL, University of London, UK and since 2020 she is full professor at the group Human Media Interaction at the Faculty EEMCS, University of Twente, the Netherlands.

\section{ORCID}

Guida Veiga (D) http://orcid.org/0000-0002-0575-1757

Rachel O'Connor (D) http://orcid.org/0000-0002-5279-3028

Carolien Rieffe (iD http://orcid.org/0000-0002-7584-6698

\section{References}

Bandura, A. (1973). Aggression: A social learning analysis. Oxford: Prentice-Hall.

Baron, R. A., \& Richardson, D. R. (2004). Human aggression (2nd ed.). New York: Plenum Press.

Barth, J. M., \& Parke, R. D. (1993). Parent-child relationship influences on children's transition to school. Merrill-Palmer Quarterly, 39(2), 173-195.

Bjorklund, D. F., \& Pellegrini, A. D. (2000). Child development and evolutionary psychology. Child Development, 71(6), 1687-1708. doi:10.1111/1467-8624.00258

Bjorklund, D. F., Periss, V., \& Causey, K. (2009). The benefits of youth. European Journal of Developmental Psychology, 6(1), 120-137. doi:10.1080/17405620802602334

Boulton, M. J., \& Smith, P. K. (1995). The social nature of play fighting and play chasing: Mechanisms and strategies underlying cooperation and compromise. In J. H. Barkow, L. Cosmides, \& J. Tooby (Eds.), Adapted mind: Evolutionary psychology and the generation of culture (pp. 22-44). New York: Oxford University Press.

Boyd, B. J. (1997). Teacher response to superhero play: To ban or not to ban? Childhood Education, 74(1), 23-28. doi:10. 1080/00094056.1997.10521909

Bradley, S. (2000). Affect regulation and the development of psychopathology. New York: Guilford Press.

Brislin, R. W. (1986). The wording and translation of research instruments. In W. J. Lonner \& J. W. Berry (Eds.), Field methods in cross-cultural research. Cross-cultural research and methodology series (Vol. 8, pp. 137-164). Thousand Oaks, CA: Sage Publications, Inc.

Burgdorf, J., Kroes, R. A., \& Moskal, J. R. (2017). Rough-and-tumble play induces resilience to stress in rats. Neuro Report. Neuro Report, 27(17), 1122-1126. doi:10.1097/WNR.0000000000000864

Carraro, A., \& Gobbi, E. (2018). Play fighting to cope with children aggression: A study in primary school. Journal of Physical Education and Sport, 18(3), 1455-1458. doi:10.7752/jpes.2018.03215

Carraro, A., Gobbi, E., \& Moè, A. (2014). Brief report: Play fighting to curb self-reported aggression in young adolescents. Journal of Adolescence, 37(8), 1303-1307. doi:10.1016/j.adolescence.2014.09.009

Carson, J. L., \& Parke, R. D. (1996). Reciprocal negative affect in parent-child interactions and children's peer competency. Child Development, 67(5), 2217-2226. doi:10.2307/1131619

Chaplin, T. M., \& Aldao, A. (2013). Gender differences in emotion expression in children: A meta-analytic review. Psychological Bulletin, 139(4), 735-765. doi:10.1037/a0030737

Cherney, I. D. (2018). Characteristics of masculine and feminine toys and gender-differentiated play. In E. S. Weisgram, \& L. M. Dinella (Eds.), Gender typing of children's toys: How early play experiences impact development (pp. 73-93). American Psychological Association. doi:10.1037/0000077-005

Colwell, M. J., \& Lindsey, E. W. (2005). Preschool children's pretend and physical play and sex of play partner: Connections to peer competence. Sex Roles, 52(7-8), 497-509. doi:10.1007/s11199-005-3716-8

Crick, N. R., Casas, J. F., \& Mosher, M. (1997). Relational and overt aggression in preschool. Developmental Psychology, 33 (4), 579-588. doi:10.1037/0012-1649.33.4.579 
Crick, N. R., Ostrov, J. M., Burr, J. E., Cullerton-Sen, C., Jansen-Yeh, E., \& Ralston, P. (2006). A longitudinal study of relational and physical aggression in preschool. Journal of Applied Developmental Psychology, 27(3), 254-268. doi:10.1016/j. appdev.2006.02.006

Dodge, K. A., \& Coie, J. D. (1987). Social-information-processing factors in reactive and proactive aggression in children's peer groups. Journal of Personality and Social Psychology, 53(6), 1146-1158. doi:10.1037/0022-3514.53.6.1146

Dubé, A. (2012). Qualité des jeux de bataille père-enfant et adaptation sociale de l'enfant d'âge préscolaire. Université de Montréal. Retrieved from http://hdl.handle.net/1866/6269

Eisenberg, N. (2000). Emotion, regulation, and moral development. Annual Review of Psychology, 51(1), 665-697. doi:10. 1146/annurev.psych.51.1.665

Ferguson, T. J., \& Eyre, H. L. (2000). Engendering gender differences in shame and guilt: Stereotypes, socialization, and situational pressures. In A. H. Fischer (Ed.), Gender and emotion: Social psychological perspectives (pp. 254-276). Cambridge: Cambridge University Press.

Flanders, J. L., Herman, K., Paquette, D., Narvaez, D., Panksepp, J., Schore, A., ... Gleason, T. (2013). Rough-and-tumble play and the cooperation-competition dilemma: Evolutionary and developmental perspectives on the development of social competence. In D. Narvaez, J. Panksepp, A. Schore, \& T. Gleason (Eds.), Evolution, early experience and human development: From research to practice and policy (pp. 371-387). New York: Oxford University Press.

Flanders, J. L., Leo, V., Paquette, D., Pihl, R. O., \& Séguin, J. R. (2009). Rough-and-tumble play and the regulation of aggression: An observational study of father-child play dyads. Aggressive Behavior, 35(4), 285-295. doi:10.1002/ab. 20309

Flanders, J. L., Simard, M., Paquette, D., Parent, S., Vitaro, F., Pihl, R. O., ... Séguin, J. R. (2010). Rough-and-tumble play and the development of physical aggression and emotion regulation: A five-year follow-Up study. Journal of Family Violence, 25(4), 357-367. doi:10.1007/s10896-009-9297-5

Fletcher, R., StGeorge, J., \& Freeman, E. (2013). Rough and tumble play quality: Theoretical foundations for a new measure of father-child interaction. Early Child Development and Care, 183(6), 746-759. doi:10.1080/03004430. 2012.723439

Fliek, L., Daemen, E., Roelofs, J., \& Muris, P. (2015). Rough-and-tumble play and other parental factors as correlates of anxiety symptoms in preschool children. Journal of Child and Family Studies, 24(2795-2804), 2795-2804. doi:10. 1007/s10826-014-0083-5

Fry, D. P. (1990). Play aggression among Zapotec children: Implications for the practice hypothesis. Aggressive Behavior, 16(5), 321-340. doi:10.1002/1098-2337(1990)16:5<321::AID-AB2480160504>3.0.CO;2-D

Halberstadt, A. G., Beale, K. S., Meade, A. W., Craig, A. B., \& Parker, A. E. (2015). Anger in families: Individual and dyadic contributions. Journal of Social and Personal Relationships, 32(6), 810-828. doi:10.1177/0265407514552617

Hart, C. H., DeWolf, D. M., Wozniak, P., \& Burts, D. C. (1992). Maternal and paternal disciplinary styles: Relations with preschoolers' playground behavioral orientations and peer status. Child Development, 63(4), 879-892. doi:10.2307/ 1131240

Hart, J. L., \& Tannock, M. T. (2018). Rough play: Past, present, and potential. In P. K. Smith (Ed.), Cambridge Handbook of play: Developmental and disciplinary perspectives (pp. 200-221). doi:10.1017/9781108131384

Hol, T., Van den Berg, C. L., Van Ree, J. M., \& Spruijt, B. M. (1999). Isolation during the play period in infancy decreases adult social interactions in rats. Behavioural Brain Research, 100(1), 91-97. doi:10.1016/S0166-4328(98)00116-8

Holland, P. (2003). We don't play with guns here: War, weapons and superhero play in the early years. Maidenhead: Open University Press.

Ladd, G. W., \& Price, J. M. (1987). Predicting children's social and school adjustment following the transition from preschool to kindergarten. Child Development, 58(5), 1168-1189. doi:10.2307/1130613.

Lillard, A. S., Lerner, M. D., Hopkins, E. J., Dore, R. A., Smith, E. D., \& Palmquist, C. M. (2013). The impact of pretend play on children's development: A review of the evidence. Psychological Bulletin, 139(1), 1-34. doi:10.1037/a0029321

Lindsey, E. W., \& Colwell, M. J. (2013). Pretend and physical play: Links to preschoolers' affective social competence. Merrill-Palmer Quarterly, 59(3), 330-360. doi:10.13110/merrpalmquar1982.59.3.0330

Logue, M. E., \& Harvey, H. (2009). Preschool teachers' views of active play. Journal of Research in Childhood Education, 24 (1), 32-49. doi:10.1080/02568540903439375

MacDonald, K., \& Parke, R. D. (1986). Parent-child physical play: The effects of sex and age of children and parents. Sex Roles, 15(7-8), 367-378. doi:10.1007/BF00287978

Nabuzoka, D., \& Smith, P. K. (1999). Distinguishing serious and playful fighting by children with learning disabilities and nondisabled children. Journal of Child Psychology and Psychiatry, 40(6), 883-890. doi:10.1111/1469-7610.00506

Nakagawa, A., \& Sukigara, M. (2014). The effects of soothing techniques and rough-and-tumble play on the early development of temperament: A longitudinal study of infants. Child Development Research, 2014, 1-10. doi:10.1155/2014/ 741373

Ostrov, J. M., \& Keating, C. F. (2004). Gender differences in preschool aggression during free play and structured interactions: An observational study. Social Development, 13(2), 255-277. doi:10.1111/j.1467-9507.2004.000266.x

Panksepp, J. (1998). Affective neuroscience: The foundations of human and animal emotions. New York: Oxford University Press. 
Panksepp, J., Burgdorf, J., Turner, C., \& Gordon, N. (2003). Modeling ADHD-type arousal with unilateral frontal cortex damage in rats and beneficial effects of play therapy. Brain and Cognition, 52(1), 97-105. doi:10.1016/S0278-2626(03)00013-7

Paquette, D. (2004). Theorizing the father-child relationship: Mechanisms and developmental outcomes. Human Development, 47(4), 193-219. doi:10.1159/000078723

Paquette, D., Carbonneau, R., Dubeau, D., Bigras, M., \& Tremblay, R. E. (2003). Prevalence of father-child rough-andtumble play and physical aggression in preschool children. European Journal of Psychology of Education, 18(2), 171-189. doi:10.1007/BF03173483

Pellegrini, A. D. (1988). Elementary-school children's rough-and-tumble play and social competence. Developmental Psychology, 24(6), 802-806. doi:10.1037/0012-1649.24.6.802

Pellegrini, A. D. (1989). Elementary school children's rough-and-tumble play. Early Childhood Research Quarterly, 4(2), 245-260. doi:10.1016/S0885-2006(89)80006-7

Pellegrini, A. D., \& Perlmutter, J. C. (1988). The diagnostic and therapeutic roles of children's rough-and-tumble play. Children's Health Care, 16(3), 162-168. doi:10.1207/s15326888chc1603_6

Pellegrini, A. D., Roseth, C. J., Mliner, S., Bohn, C., Van Ryzin, M., Vance, N., .. Tarullo, A. (2007). Social dominance in preschool classrooms. Journal of Comparative Psychology, 121(1), 54-64. doi:10.1037/0735-7036.121.1.54

Pellegrini, A. D., \& Smith, P. K. (1998). Physical activity play: The nature and function of a neglected aspect of play. Child Development, 69(3), 577-598. doi:10.2307/1132187

Pellis, S. M., \& Pellis, V. C. (2007). Rough-and-tumble play and the development of the social brain. Current Directions in Psychological Science, 16(2), 95-98. doi:10.1111/j.1467-8721.2007.00483.x

Pellis, S. M., \& Pellis, V. C. (2012). Play-fighting during early childhood and its role in preventing later chronic aggression. In R. E. Tremblay, M. Boivin, \& R. Peters (Eds.), Encyclopedia on early childhood development. Centre of Excellence for Early Childhood Development and Strategic Knowledge Cluster on Early Child Development. Retrieved from http:// www.child-encyclopedia.com/pages/PDF/PellisANGxp1.pdf

Pellis, S. M., Pellis, V. C., \& Reinhart, C. (2010). The evolution of social play. In C. Worthman, P. Plotsky, D. Schechter, \& C. Cummings (Eds.), Formative experiences: The interaction of caregiving, culture, and developmental psychobiology (pp. 404-431). Cambridge: Cambridge University Press. doi:10.1017/CBO9780511711879.037.

Perlman, S. B., \& Pelphrey, K. A. (2011). Developing connections for affective regulation: Age-related changes in emotional brain connectivity. Journal of Experimental Child Psychology, 108(3), 607-620. doi:10.1016/j.jecp.2010.08.006

Peterson, J. B., \& Flanders, J. L. (2005). Play and the regulation of aggression. In R. E. Tremblay, W. H. Hartup, \& J. Archer (Eds.), Developmental origins of aggression (pp. 133-157). New York: Guilford Press. Retrieved from http://psycnet.apa. org/psycinfo/2005-09268-007.

Rieffe, C., Ketelaar, L., \& Wiefferink, C. H. (2010). Assessing empathy in young children: Construction and validation of an Empathy Questionnaire (EmQue). Personality and Individual Differences, 49(5), 362-367. doi:10.3389/fpsyg.2017.00870

Roberton, T., Daffern, M., \& Bucks, R. S. (2012). Emotion regulation and aggression. Aggression and Violent Behavior, 17(1), 72-82. doi:10.1016/j.avb.2011.09.006

Romero, G. A., Pham, M. N., \& Goetz, A. T. (2014). The implicit rules of combat. Human Nature, 25(4), 496-516. doi:10. 1007/s12110-014-9214-3

Ross, H., \& Taylor, H. (1989). Do boys prefer daddy or his physical style of play? Sex Roles, 20(1-2), 23-33. doi:10.1007/ BF00288024

Rydell, R. J., Mackie, D. M., Maitner, A. T., Claypool, H. M., Ryan, M. J., \& Smith, E. R. (2008). Arousal, processing, and risk taking: Consequences of intergroup anger. Personality and Social Psychology Bulletin, 34(8), 1141-1152. doi:10.1177/ 0146167208319694

Scarlett, W. G., Naudeau, S., Salonius-Pasternak, D., \& Ponte, I. (2005). Children's play. London: SAGE Publications.

Scott, E., \& Panksepp, J. (2003). Rough-and-tumble play in human children. Aggressive Behavior, 29(6), 539-551. doi:10. 1002/ab.10062

Smith, P. K., Smees, R., \& Pellegrini, A. D. (2004). Play fighting and real fighting: Using video playback methodology with young children. Aggressive Behavior, 30(2), 164-173. doi:10.1002/ab.20013

StGeorge, J., \& Freeman, E. (2017). Measurement of father-child rough-and-tumble play and its relations to child behavior. Infant Mental Health Journal, 28(6), 709-725. doi:10.1007/s10826-017-0993-0

Storli, R. (2013). Characteristics of indoor rough-and-tumble play (R\&T) with physical contact between players in preschool. Nordic Early Childhood Education Research Journal, 6(16), 1-14. doi:10.7577/nbf.342

Tremblay, R. E. (2000). The development of aggressive behaviour during childhood: What have we learned in the past century? International Journal of Behavioral Development, 24(2), 129-141. doi:10.1080/016502500383232

Tremblay, R. E. (2006). Prevention of youth violence: Why not start at the beginning? Journal of Abnormal Child Psychology, 34(4), 480-486. doi:10.1007/s10802-006-9038-7

Van den Berg, C. L., Hol, T., Van Ree, J. M., Spruijt, B. M., Everts, H., \& Koolhaas, J. M. (1999). Play is indispensable for an adequate development of coping with social challenges in the rat. Developmental Psychobiology, 34(2), $129-138$. doi:10.1002/(SICI)1098-2302(199903)34:2<129::AID-DEV6>3.0.CO;2-L

Veiga, G., de Leng, W., Cachucho, R., Ketelaar, L., Kok, J. N., Knobbe, A., ... Rieffe, C. (2016). Social competence at the playground: Preschoolers during recess. Infant and Child Development, 26(1), e1957. doi:10.1002/icd.1957.

Zillman, D. (1979). Hostility and aggression. Hillsdale, NJ: Lawrence Erlbaum. 